\title{
Coupled and tripled coincidence point results without compatibility
}

\author{
Nawab Hussain ${ }^{1}$, Abdul Latif ${ }^{1 *}$ and Masood Hussain Shah ${ }^{2}$
}

* Correspondence: alatif@kau.edu. sa

'Department of Mathematics, King Abdulaziz University, P. O. Box 80203, Jeddah 21589, Saudi Arabia Full list of author information is available at the end of the article

\begin{abstract}
In this article, we introduce a new and simple approach to coupled and tripled coincidence point theory. By using our method, we establish coupled coincidence point results of Lakshmikantham and Ćirić, Binayak et al., Alotaibi and Alsulami without any type of commutativity condition on $F$ and $g$. We also use our technique to prove tripled coincidence point results of Borcut and Berinde without commutativity of maps. Also, we give a supporting example of non-commuting, non-compatible mappings where the above mentioned results can not be applied. Mathematics Subject Classification: Primary, 47H10; Secondary, 54H25; 34B15.
\end{abstract}

Keywords: coupled coincidence point, tripled coincidence point, partially ordered set, mixed $g$-monotone mapping

\section{Introduction}

Existence of a fixed point for contraction type mappings in partially ordered metric spaces has been considered recently by Ran and Reurings [1], Agarwal et al. [2], Bhaskar and Lakshmikantham [3], Nieto and López [4], and Luong and Thuan [5].

Using the concept of commuting maps and mixed $g$-monotone property, Lakshmikantham and Ćirić [6] established the existence of coupled coincidence point results to generalize the results of Bhaskar and Lakshmikantham [3]. Binayak et al. [7] generalized these results to a pair of compatible maps. Recently, Alotaibi and Alsulami [8] extended the results in [5] for a compatible pair. Very recently, Borcut and Berinde [9] proved tripled coincidence point results for commuting maps. In this article, we prove the above mentioned coupled and tripled coincidence results without any type of commutativity condition on $F$ and $g$. At the end, we give a supporting example of noncommuting, non-compatible mappings where the above mentioned results can not be applied.

\section{Main results}

Recall that if $(X, \leq)$ is a partially ordered set and $F: X \rightarrow X$ is such that for $x, y \in X, x$ $\leq y$ implies $F(x) \leq F(y)$, then mapping $F$ is said to be non-decreasing. Similarly, a non-increasing mapping may be defined. Bhaskar and Lakshmikantham [3] introduced the following notions of a mixed monotone mapping and a coupled fixed point (see also [10-12]).

Definition 2.1 [3] Let $(X, \leq)$ be a partially ordered set and $F: X \times X \rightarrow X$. The mapping $F$ is said to have the mixed monotone property if $F$ is monotone non-decreasing

(C) 2012 Hussain et al; licensee Springer. This is an Open Access article distributed under the terms of the Creative Commons Attribution License (http://creativecommons.org/licenses/by/2.0), which permits unrestricted use, distribution, and reproduction in any medium, provided the original work is properly cited. 
in its first and monotone non-increasing in its second argument, that is, for any $x, y \in$ $X$,

$$
x_{1}, x_{2} \in X, x_{1} \leq x_{2} \Rightarrow F\left(x_{1}, y\right) \leq F\left(x_{2}, y\right)
$$

and

$$
y_{1}, y_{2} \in X, y_{1} \leq y_{2} \Rightarrow F\left(x, y_{1}\right) \geq F\left(x, y_{2}\right)
$$

Definition 2.2 [3] An element $(x, y) \in X \times X$ is called a coupled fixed point of the mapping $F: X \times X \rightarrow X$ if

$$
F(x, y)=x, \quad F(y, x)=y .
$$

Analogous to Definition 2.1, Lakshmikantham and Ćirić [6] introduced the following concept of a mixed $g$-monotone mapping.

Definition 2.3. [6] Let $(X, \leq)$ be a partially ordered set, $F: X \times X \rightarrow X$ and $g: X \rightarrow$ $X$. We say $F$ has the mixed $g$-monotone property if $F$ is monotone $g$-non-decreasing in its first argument and is monotone $g$-non-increasing in its second argument, that is, for any $x, y \in X$,

$$
x_{1}, x_{2} \in X, g\left(x_{1}\right) \leq g\left(x_{2}\right) \text { implies } F\left(x_{1}, y\right) \leq F\left(x_{2}, y\right)
$$

and

$$
y_{1}, y_{2} \in X, g\left(y_{1}\right) \leq g\left(y_{2}\right) \text { implies } F\left(x, y_{1}\right) \geq F\left(x, y_{2}\right) .
$$

Note that if $g$ is the identity mapping, then Definition 2.3 reduces to 2.1.

Definition 2.4. [6] An element $(x, y) \in X \times X$ is called a coupled coincidence point of the mappings $F: X \times X \rightarrow X$ and $g: X \rightarrow X$ if

$$
F(x, y)=g(x), F(y, x)=g(y) .
$$

Definition 2.5. [6] Let $X$ be a non-empty set and $F: X \times X \rightarrow X$ and $g: X \rightarrow X$. We say $F$ and $g$ are commutative if

$$
g(F(x, y))=F(g(x), g(y))
$$

for all $x, y \in X$.

Definition 2.6. [7] The mappings $F: X \times X \rightarrow X$ and $g: X \rightarrow X$, are said to be compatible if

$$
\lim _{n \rightarrow \infty} d\left(g\left(F\left(x_{n}, y_{n}\right)\right), F\left(g x_{n}, g y_{n}\right)\right)=0
$$

and

$$
\lim _{n \rightarrow \infty} d\left(g\left(F\left(y_{n}, x_{n}\right)\right), F\left(g y_{n}, g x_{n}\right)\right)=0,
$$

whenever $\left\{x_{n}\right\}$ and $\left\{y_{n}\right\}$ are sequences in $X$, such that $\lim _{n \rightarrow \infty} F\left(x_{n}, y_{n}\right)=\lim _{n \rightarrow \infty} g x_{n}$ $=x$ and $\lim _{n \rightarrow \infty} F\left(y_{n}, x_{n}\right)=\lim _{n \rightarrow \infty} g y_{n}=x$, for all $x, y \in X$ are satisfied.

We shall need the following known results.

Lemma 2.7. [13] Let $X$ be a nonempty set and $g: X \rightarrow X$ be a mapping. Then, there exists a subset $E \subseteq X$ such that $g(E)=g(X)$ and $g: E \rightarrow X$ is one-to-one. 
Corollary 2.8. [6] Let $(X, \leq)$ be a partially ordered set and suppose there is a metric $d$ on $X$ such that $(X, d)$ is a complete metric space. Assume there is a function $\phi:[0$, $+\infty) \rightarrow[0,+\infty)$ with $\phi(t)<t$ and $\lim _{r \rightarrow t+} \phi(r)<t$ for each $t>0$ and also suppose $F: X$ $\times X \rightarrow X$ has the mixed monotone property and

$$
d(F(x, y), F(u, v)) \leq \varphi\left(\frac{d(x, u)+d(y, v)}{2}\right)
$$

for all $x, y, u, v \in X$ for which $x \leq u$ and $y \geq v$. Suppose either

(a) $F$ is continuous or

(b) $X$ has the following property:

(i) if a non-decreasing sequence $\left\{x_{n}\right\} \rightarrow x$, then $x_{n} \leq x$ for all $n$,

(ii) if a non-increasing sequence $\left\{y_{n}\right\} \rightarrow y$, then $y \leq y_{n}$ for all $n$.

If there exists $x_{0}, y_{0} \in X$ such that

$$
x_{0} \leq F\left(x_{0}, y_{0}\right) \text { and } y_{0} \geq F\left(y_{0}, x_{0}\right),
$$

then there exist $x, y \in X$ such that

$$
x=F(x, y) \text { and } y=F(y, x),
$$

that is, $F$ has a coupled fixed point.

First, we establish main results of Lakshmikantham and Ćirić [6] and Choudhury and Kundu [7] without any type of commutativity of the maps $F$ and $g$.

Theorem 2.9. Let $(X, \leq, d)$ be a partially ordered metric space. Assume there is a function $\phi:[0,+\infty) \rightarrow[0,+\infty)$ with $\phi(t)<t$ and $\lim _{r \rightarrow t+} \phi(r)<t$ for each $t>0$ and also suppose $F: X \times X \rightarrow X$ and $g: X \rightarrow X$ are such that $g(X)$ is complete and $F$ has the mixed $g$-monotone property and

$$
d(F(x, y), F(u, v)) \leq \varphi\left(\frac{d(g(x), g(u))+d(g(y), g(v))}{2}\right)
$$

for all $x, y, u, v \in X$ for which $g(x) \leq g(u)$ and $g(y) \geq g(v)$. Suppose $F(X \times X) \subseteq g(X)$, $g$ is continuous and also suppose either

(a) $F$ is continuous or

(b) $X$ has the following property:

(i) if a non-decreasing sequence $\left\{x_{n}\right\} \rightarrow x$, then $x_{n} \leq x$ for all $n$,

(ii) if a non-increasing sequence $\left\{y_{n}\right\} \rightarrow y$, then $y \leq y_{n}$ for all $n$.

If there exists $x_{0}, y_{0} \in X$ such that

$$
g\left(x_{0}\right) \leq F\left(x_{0}, y_{0}\right) \text { and } g\left(y_{0}\right) \geq F\left(y_{0}, x_{0}\right),
$$

then there exist $x, y \in X$ such that

$$
g(x)=F(x, y) \text { and } g(y)=F(y, x),
$$

that is, $F$ and $g$ have a coupled coincidence. 
Proof. Using Lemma 2.7, there exists $E \subseteq X$ such that $g(E)=g(X)$ and $g: E \rightarrow X$ is one-to-one. We define a mapping $G: g(E) \times g(E) \rightarrow X$ by

$$
G(g x, g y)=F(x, y)
$$

for all $g x, g y \in g(E)$. As $g$ is one-to-one on $g(E)$, so $G$ is well-defined. Thus, it follows from (1) and (2) that

$$
d(G(g x, g y), G(g u, g v))=d(F(x, y), F(u, v)) \leq \varphi\left(\frac{d(g(x), g(u))+d(g(y), g(v))}{2}\right)
$$

for all $g x, g y, g u, g v \in g(X)$ for which $g(x) \leq g(u)$ and $g(y) \geq g(v)$. Since $F$ has the mixed $g$-monotone property, for all $g x, g y \in g(X)$,

$$
g x_{1}, g x_{2} \in g(X), g\left(x_{1}\right) \leq g\left(x_{2}\right) \text { implies } G\left(g x_{1}, g y\right) \leq G\left(g x_{2}, g y\right)
$$

and

$$
g y_{1}, g y_{2} \in g(X), g\left(y_{1}\right) \leq g\left(y_{2}\right) \text { implies } G\left(g x, g y_{1}\right) \geq G\left(g x, g y_{2}\right) .
$$

which imply that $G$ has the mixed monotone property. Also there exist $x_{0}, y_{0} \in X$ such that

$$
g\left(x_{0}\right) \leq F\left(x_{0}, y_{0}\right) \text { and } g\left(y_{0}\right) \geq F\left(y_{0}, x_{0}\right) .
$$

This implies there exist $g x_{0}, g y_{0} \in g(X)$ such that

$$
g\left(x_{0}\right) \leq G\left(g x_{0}, g y_{0}\right) \text { and } g\left(y_{0}\right) \geq G\left(g y_{0}, g x_{0}\right),
$$

Suppose that the assumption (a) holds. Since $F$ is continuous, $G$ is also continuous. Using Corollary 2.8 to the mapping $G$, it follows that $G$ has a coupled fixed point ( $u$, $v) \in g(X) \times g(X)$

Suppose that the assumption $(b)$ holds. We conclude similarly that the mapping $G$ has a coupled fixed point $(u, v) \in g(X) \times g(X)$. Finally, we prove that $F$ and $g$ have a coupled coincidence point. Since $(u, v)$ is a coupled fixed point of $G$, we get

$$
u=G(u, v) \text { and } v=G(v, u) .
$$

Since $(u, v) \in g(X) \times g(X)$, there exists a point $\left(u_{0}, v_{0}\right) \in X \times X$ such that

$$
u=g u_{0} \text { and } v=g v_{0} \text {. }
$$

It follows from (5) and (6) that

$$
g u_{0}=G\left(g u_{0}, g v_{0}\right) \text { and } g v_{0}=G\left(g v_{0}, g u_{0}\right) .
$$

Combining (2) and (7) we get

$$
g u_{0}=F\left(u_{0}, v_{0}\right) \text { and } g v_{0}=F\left(v_{0}, u_{0}\right) .
$$

Thus, $\left(u_{0}, v_{0}\right)$ is a required coupled coincidence point of $F$ and $g$. This completes the proof.

Theorem 2.10. Let $F: X \times X \rightarrow X, g: X \rightarrow X$ be such that all the conditions of Theorem 2.9 hold except the completeness of $g(X)$. Let $X$ be complete and $g$ be onto. Then $F$ and $g$ have a coupled coincidence point. 
Proof. As in the proof of Theorem 2.9, there exists $E \subseteq X$ such that $g(E)=g(X)$. As $g$ is onto so $X=g(X)$. Now the conclusion follows from Theorem 2.9.

As in [5], let $\Phi$ denote all functions $\varphi:[0, \infty) \rightarrow[0, \infty)$ which satisfy

(1) $\varphi$ is continuous and non-decreasing,

(2) $\varphi(t)=0$ if and only if $t=0$,

(3) $\varphi(t+s) \leq \varphi(t)+\varphi(s), \forall t, s \in[0, \infty)$

and let $\Psi$ denote all function $\psi:[0, \infty) \rightarrow(0, \infty)$ which satisfy $\lim _{t \rightarrow r} \psi(t)>0$ for all $r$ $>0$ and $\lim _{t \rightarrow 0^{+}} \psi(t)=0$.

Recently, Luong and Thuan [5] presented some coupled fixed point theorems for a mixed monotone mapping in a partially ordered metric space which are generalizations of the results of Bhaskar and Lakshmikantham [3]. Alotaibi and Alsulami [8] extended Luong and Thuan main result to coupled coincidences using the notion of compatible maps. Here we prove this result without the condition of compatible maps.

Theorem 2.11. Let $(X, \leq, d)$ be a partially ordered metric space and $F: X \times X \rightarrow X$ and $g: X \rightarrow X$ be a mapping having the mixed $g$-monotone property on $X$. Suppose that there exist two elements $x_{0}, y_{0} \in X$ such that

$$
g x_{0} \leq F\left(x_{0}, y_{0}\right) \text { and } g y_{0} \geq F\left(y_{0}, x_{0}\right) .
$$

Suppose there exist $\varphi \in \Phi$ and $\psi \in \Psi$ such that

$$
\phi(d(F(x, y), F(u, v))) \leq \frac{1}{2} \phi(d(g x, g u)+d(g y, g v))-\psi\left(\frac{d(g x, g u)+d(g y, g v))}{2}\right)
$$

for all $x, y, u, v \in X$ with $g x \leq g u$ and $g y \geq g \nu$. Suppose $F(X \times X) \subseteq g(X), g$ is continuous, $g(X)$ is complete and also suppose either

(a) $F$ is continuous or

(b) $X$ has the following property:

(i) if a non-decreasing sequence $\left\{x_{n}\right\} \rightarrow x$, then $x_{n} \leq x$, for all $n$,

(ii) if a non-increasing sequence $\left\{y_{n}\right\} \rightarrow y$, then $y \leq y_{n}$, for all $n$,

then there exist $x, y \in X$ such that

$$
g x=F(x, y) \text { and } g y=F(y, x)
$$

that is, $F$ and $g$ have a coupled coincidence point.

Proof. As in the proof of Theorem 2.9, we define a mapping $G: g(X) \times g(X) \rightarrow X$ by

$$
G(g x, g y)=F(x, y)
$$

for all $g x, g y \in g(X)$ which satisfies all the conditions of Theorem 2.1 [5] on $g(X)$, so $G$ has a coupled fixed point which is a coupled coincidence point of $F$ and $g$.

Theorem 2.12. Let $F: X \times X \rightarrow X, g: X \rightarrow X$ be such that all the conditions of Theorem 2.11 hold except the completeness of $g(X)$. Let $X$ be complete and $g$ be onto. Then $F$ and $g$ have a coupled coincidence point.

Proof. As in the proof of Theorem 2.11, there exists $E \subseteq X$ such that $g(E)=g(X)$. As $g$ is onto so $X=g(X)$, now the conclusion follows from Theorem 2.11.

Let $(X, \leq)$ be a partially ordered set. Consider on the product space $X \times X \times X \rightarrow X$, the following partial order: 
$(u, v, w) \leq(x, y, z) \Leftrightarrow x \geq u, y \leq v, \quad z \geq w$,

for $(x, y, z),(u, v, w) \in X \times X \times X \rightarrow X$.

Let $X$ be a nonempty set and $F: X \times X \times X \rightarrow X$ be a map. An element $(x, y, z) \in X$ $\times X \times X$ is called a tripled fixed point of $F$ if

$$
F(x, y, z)=x, \quad F(y, z, x)=y, \quad F(z, x, y)=z
$$

Note that if $(x, y, z)$ is a tripled fixed point of $F$, then $(y, z, x)$ and $(z, x, y)$ are tripled fixed points of $F$ too.

An element $(x, y, z) \in X \times X \times X$ is called a tripled coincidence point of the mappings $F: X \times X \times X \rightarrow X$ and $g: X \rightarrow X$ if

$$
F(x, y, z)=g x, \quad F(y, z, x)=g y, \quad F(z, x, y)=g z .
$$

Let $F: X \times X \times X \rightarrow X$ and $g: X \rightarrow X$. We say $F$ and $g$ are commutative if

$$
g F(x, y, z)=F(g x, g y, g z)
$$

for all $x, y, z \in X$.

Definition 2.13. [14] Let $(X, \leq)$ be a partially ordered set and $F: X \times X \times X \rightarrow X$ and $g: X \rightarrow X$. We say $F$ has the mixed $g$-monotone property if $F$ is monotone $g$-nondecreasing in its first and third argument and is monotone $g$-non-increasing in its second argument, that is, for any $x, y, z \in X$,

$$
\begin{aligned}
& x_{1}, x_{2} \in X, g\left(x_{1}\right) \leq g\left(x_{2}\right) \text { implies } F\left(x_{1}, y, z\right) \leq F\left(x_{2}, y, z\right) \\
& y_{1}, y_{2} \in X, g\left(y_{1}\right) \leq g\left(y_{2}\right) \text { implies } F(x, y, z) \geq F(x, y, z) \\
& z_{1}, z_{2} \in X, g\left(z_{1}\right) \leq g\left(z_{2}\right) \text { implies } F\left(x, y, z_{1}\right) \geq F\left(x, y, z_{2}\right) .
\end{aligned}
$$

In a very recent article [9], Borcut and Berinde established some results regarding the tripled coincidence point for commuting operators $F: X \times X \times X \rightarrow X$ and $g: X \rightarrow X$. We prove these tripled coincidence point results without any type of commutativity conditions on $F$ and $g$.

Theorem 2.14. Let $(X, \leq, d)$ be a partially ordered metric space. Let $F: X \times X \times X \rightarrow$ $X$ and $g: X \rightarrow X$ be mappings having the mixed $g$-monotone property on $X$ such that there exist elements $x_{0}, y_{0}, z_{0} \in X$ with

$$
g x_{0} \leq F\left(x_{0}, y_{0}, z_{0}\right) \quad, \quad g y_{0} \geq F\left(y_{0}, x_{0}, z_{0}\right) \text { and } g z_{0} \leq F\left(z_{0}, y_{0}, x_{0}\right) .
$$

Assume that there exist $j, k, l \in[0,1)$ with $j+k+l<1$ such that

$$
d(F(x, y, z), F(u, v, w)) \leq j d(g x, g u)+k d(g y, g v)+l d(g z, g w)
$$

for all $x, y, z, u, v, w \in X$ with $g x \leq g u, g z \leq g w$ and $g y \geq g v$. Suppose $F(X \times X \times X)$ $\subseteq g(X), g$ is continuous, $g(X)$ is complete and also suppose either
(a) $F$ is continuous or
(b) $X$ has the following property:

(i) if a non-decreasing sequence $\left\{x_{n}\right\} \rightarrow x$, then $x_{n} \leq x$, for all $n$,

(ii) if a non-increasing sequence $\left\{y_{n}\right\} \rightarrow y$, then $y_{n} \geq y$, for all $n$ 
(iii) if a non-increasing sequence $\left\{z_{n}\right\} \rightarrow z$, then $z_{n} \leq z$, for all $n$

then there exist $x, y, z \in X$ such that

$$
g x=F(x, y, z), \quad g y=F(y, z, x) \text { and } g z=F(z, x, y)
$$

that is, $F$ and $g$ have a tripled coincidence point.

Proof. By Lemma 2.7, there exists $E \subseteq X$ such that $g(E)=g(X)$ and $g: E \rightarrow X$ is oneto-one. We define a mapping $G: g(X) \times g(X) \times g(X) \rightarrow X$ by

$$
G(g x, g y, g z)=F(x, y, z),
$$

As $g$ is one-to-one on $g(X)$, so $G$ is well-defined. Thus, it follows from (14) and (15) that

$d(G(g x, g y, g z), G(g u, g v, g z))=d(F(x, y, z), F(u, v, w)) \leq j d(g x, g u)+k d(g y, g v)+l d(g z, g w)$

for all $g x, g y, g z, g u, g v, g w \in g(X)$ for which $g(x) \leq g(u), g(z) \leq g(w)$ and $g(y) \geq g(v)$. Since $F$ has the mixed $g$-monotone property, for all $g x, g y, g z \in g(X)$,

$$
g x_{1}, g x_{2} \in g(X), g\left(x_{1}\right) \leq g\left(x_{2}\right) \text { implies } G\left(g x_{1}, g y, g z\right) \leq G\left(g x_{2}, g y, g z\right)
$$

and

$$
g y_{1}, g y_{2} \in g(X), g\left(y_{1}\right) \leq g\left(y_{2}\right) \text { implies } G\left(g x, g y_{1}, g z\right) \geq G\left(g x, g y_{2}, g z\right)
$$

and

$$
g z_{1}, g z_{2} \in g(X), g\left(z_{1}\right) \leq g\left(z_{2}\right) \text { implies } G\left(g x, g y, g z_{1}\right) \leq G\left(g x, g y, g z_{2}\right)
$$

which implies that $G$ has the mixed monotone property. Also there exist $x_{0}, y_{0}, z_{0} \in$ $X$ such that

$$
g x_{0} \leq F\left(x_{0}, y_{0}, z_{0}\right), \quad g y_{0} \geq F\left(y_{0}, x_{0}, z_{0}\right) \text { and } g z_{0} \leq F\left(z_{0}, y_{0}, x_{0}\right) .
$$

This implies there exist $g x_{0}, g y_{0}, g z_{0} \in g(X)$ such that

$$
g x_{0} \leq G\left(g x_{0}, g y_{0}, g z_{0}\right), \quad g y_{0} \geq G\left(g y_{0}, g x_{0}, g z_{0}\right) \text { and } g z_{0} \leq G\left(g z_{0}, g y_{0}, g x_{0}\right)
$$

Suppose that the assumption (a) holds. Since $F$ is continuous, $G$ is also continuous. Using Theorem 7 in [14] to the mapping $G$, it follows that $G$ has a tripled fixed point $(u, v, w) \in g(X) \times g(X) \times g(X)$.

Suppose that the assumption $(b)$ holds. We conclude in the same way that the mapping $G$ has a tripled fixed point $(u, v, w) \in g(X) \times g(X) \times g(X)$. Finally, we prove that $F$ and $g$ have a tripled coincidence point. Since $(u, v, w)$ is a tripled fixed point of $G$, we get

$$
u=G(u, v, w), v=G(v, w, u) \text { and } w=G(w, u, v) .
$$

Since $(u, v, w) \in g(X) \times g(X) \times g(X)$, there exists a point $\left(u_{0}, v_{0}, w_{0}\right) \in X \times X \times X$ such that

$$
u=g u_{0}, v=g v_{0} \text { and } w=g w_{0} .
$$


It follows from (16) and (17) that

$$
g u_{0}=G\left(g u_{0}, g v_{0}, g w_{0}\right), g v_{0}=G\left(g v_{0}, g w_{0}, g u_{0}\right) \text { and } g w_{0}=G\left(g w_{0}, g u_{0}, g v_{0}\right) \text {. }
$$

Combining (15) and (18) we get

$$
g u_{0}=F\left(u_{0}, v_{0}, w_{0}\right), g v_{0}=F\left(v_{0}, w_{0}, u_{0}\right) \text { and } g w_{0}=F\left(w_{0}, u_{0}, v_{0}\right) \text {. }
$$

Thus, $\left(u_{0}, v_{0}, w_{0}\right)$ is a required tripled coincidence point of $F$ and $g$. This completes the proof.

Remark 2.15. The conclusion of Theorem 2.14 follows from the proof of Theorem 2.10 if $X$ is complete and $g$ is onto instead of $g(X)$ is complete.

Now we state the result (proof is analogous to that of [[9], Theorem 5]); regarding the uniqueness of tripled coincidence points which extends [[9], Theorem 5].

Theorem 2.16. The addition in the hypotheses of Theorem 2.14 of the following condition: for every $(x, y, z),\left(x^{*}, y^{*}, z^{*}\right) \in X \times X \times X$ there exists a $(u, v, w) \in X \times X \times$ $X$ such that $(F(u, v, w), F(v, u, w), F(w, v, u))$ is comparable to $(g x, g y, g z)$ and to ( $g x^{*}$, $\left.g y^{*}, g z^{*}\right)$, leads to the conclusion that $F$ and $g$ have a unique tripled coincidence point.

Example 2.17. [15] Let $X=\mathbb{R}$, endowed with the usual metric and usual order. Then $(X, \leq, d)$ is a partially ordered metric space. Define mappings $F: X \times X \rightarrow X$ and $g: X$ $\rightarrow X$ by $F(x, y)=1$ for all $(x, y) \in X \times X$ and $g(x)=x-1$ for all $x \in X$. Since

$$
g(F(x, y))=g(1)=0 \neq 1=F(g x, g y)
$$

for all $x, y \in X$, the mappings $F$ and $g$ do not satisfy the commutativity condition. We show that $F$ and $g$ are not compatible. Let $\left\{x_{n}\right\}$ and $\left\{y_{n}\right\}$ be two sequences in $X$ such that $\lim _{n \rightarrow \infty} F\left(x_{n}, y_{n}\right)=a, \lim _{n \rightarrow \infty} g x_{n}=a, \lim _{n \rightarrow \infty} F\left(y_{n}, x_{n}\right)=b$ and $\lim _{n \rightarrow \infty} g y_{n}$ $=b$. Then obviously, $a=1$ and $b=1$. Further, it follows that,

$$
\lim _{n \rightarrow \infty} d\left(g\left(F\left(x_{n}, y_{n}\right)\right), F\left(g x_{n}, g y_{n}\right)\right)=1 \neq 0
$$

and

$$
\lim _{n \rightarrow \infty} d\left(g\left(F\left(y_{n}, x_{n}\right)\right), F\left(g y_{n}, g x_{n}\right)\right)=1 \neq 0,
$$

Hence, the mappings $F$ and $g$ are not compatible. Thus the results in [6-8] cannot be applied to these functions. Simple calculations show that $F(X \times X) \subseteq g(X), g$ is onto, $g X=X$ is complete, $g$ and $F$ are continuous and $F$ has the mixed $g$-monotone property. Moreover, there exist $x_{0}=1$ and $y_{0}=3$ with $g(1)=0 \leq 1=F(1,3)$ and $g(3)=2 \geq 1=$ $F(3,1)$. Therefore, all the conditions of Theorem 2.10 are satisfied and so $F$ and $g$ have a coupled coincidence point in $X \times X$. In fact, the point $(2,2)$ is a coupled coincidence point of $F$ and $g$.

\section{Acknowledgements}

The authors are indebted to the referees for their comments that undoubtedly helped us to improve the text. The first and second author gratefully acknowledge the financial support provided by University of Tabuk through the project of international cooperation with the University of Texas at El Paso.

\section{Author details}

${ }^{1}$ Department of Mathematics, King Abdulaziz University, P. O. Box 80203, Jeddah 21589, Saudi Arabia ${ }^{2}$ Department of Mathematical Sciences, LUMS, DHA Lahore, Pakistan 


\section{Competing interests}

The authors declare that they have no competing interests.

Received: 28 January 2012 Accepted: 9 May 2012 Published: 9 May 2012

\section{References}

1. Ran, ACM, Reurings, MCB: A fixed point theorem in partially ordered sets and some applications to matrix equations. Proc Am Math Soc. 132, 1435-1443 (2004). doi:10.1090/S0002-9939-03-07220-4

2. Agarwal, RP, El-Gebeily, MA, O'Regan, D: Generalized contractions in partially ordered metric spaces. Appl Anal. 87, 1-8 (2008). doi:10.1080/00036810701714164

3. Bhaskar, TG, Lakshmikantham, V: Fixed point theorems in partially ordered metric spaces and applications. Nonlinear Anal. 65, 1379-1393 (2006). doi:10.1016/j.na.2005.10.017

4. Nieto, JJ, Lopez, RR: Existence and uniqueness of fixed point in partially ordered sets and applications to ordinary differential equations. Acta Math Sinica Engl Ser. 23, 2205-2212 (2007). doi:10.1007/s10114-005-0769-0

5. Luong, NV, Thuan, NX: Coupled fixed point in partially ordered metric spaces and applications. Nonlinear Anal. 74, 983-992 (2011). doi:10.1016/j.na.2010.09.055

6. Lakshmikantham, V, Cirić, L: Coupled fixed point theorems for nonlinear contractions in partially ordered metric spaces. Nonlinear Anal. 70, 4341-4349 (2009). doi:10.1016/j.na.2008.09.020

7. Binayak, S, Kundu, CA: A coupled coincidence point result in partially ordered metric spaces for compatible mappings. Nonlinear Anal. 73, 2524-2531 (2010). doi:10.1016/j.na.2010.06.025

8. Alotaibi, A, Alsulami, SM: Coupled coincidence points for monotone operators in in partially ordered metric spaces. Fixed Point Theory Appl. 2011, 44 (2011). doi:10.1186/1687-1812-2011-44

9. Borcut, M, Berinde, V: Tripled coincidence theorems for contractive type mappings in partially ordered metric spaces. Appl Math Comput. 218, 7339-7346 (2011)

10. Hussain, N, Shah, MH, Kutbi, MA: Coupled coincidence point theorems for nonlinear contractions in partially ordered quasi-metric spaces with a Q-function. Fixed Point Theory Appl 2011, 21 (2011). (Article ID 703938). doi:10.1186/16871812-2011-21

11. Hussain, N, Alotaibi, A: Coupled coincidences for multi-valued nonlinear contractions in partially ordered metric spaces. Fixed Point Theory Appl 2011, 82 (2011). doi:10.1186/1687-1812-2011-82. doi:10.1186/1687-1812-2011-82

12. Cho, YJ, Shah, MH, Hussain, N: Coupled fixed points of weakly F-contractive mappings in topological spaces. Appl Math Lett. 24, 1185-1190 (2011). doi:10.1016/j.aml.2011.02.004

13. Haghi, RH, Rezapour, Sh, Shahzad, N: Some fixed point generalizations are not real generalizations. Nonlinear Anal. 74 1799-1803 (2011). doi:10.1016/.na.2010.10.052

14. Berinde, V, Borcut, M: Tripled fixed point theorems for contractive type mappings in partially ordered metric spaces Nonlinear Anal. 74, 4889-4897 (2011). doi:10.1016/j.na.2011.03.032

15. Sintunavarat, W, Cho, YJ, Kumam, P: Coupled coincidence point theorems for contractions without commutative condition in intuitionistic fuzzy normed spaces. Fixed Point Theory Appl. 2011, 81 (2011). doi:10.1186/1687-1812-201181

doi:10.1186/1687-1812-2012-77

Cite this article as: Hussain et al: Coupled and tripled coincidence point results without compatibility. Fixed Point Theory and Applications 2012 2012:77.

\section{Submit your manuscript to a SpringerOpen ${ }^{\circ}$ journal and benefit from:}

- Convenient online submission

Rigorous peer review

- Immediate publication on acceptance

- Open access: articles freely available online

- High visibility within the field

- Retaining the copyright to your article

Submit your next manuscript at $\boldsymbol{s p r i n g e r o p e n . c o m ~}$ 